\title{
Review Article \\ The Gut Microbiota and Oxidative Stress in Autism Spectrum Disorders (ASD)
}

\author{
Tingting Hu, Yinmiao Dong, Caixia He, Mingyi Zhao $\mathbb{D}$, and Qingnan He $\mathbb{D}$ \\ Department of Pediatrics, The Third Xiangya Hospital, Central South University, Changsha, 410013 Hunan Province, China
}

Correspondence should be addressed to Mingyi Zhao; 36163773@qq.com and Qingnan He; heqn2629@163.com

Received 26 July 2020; Revised 14 September 2020; Accepted 17 September 2020; Published 1 October 2020

Academic Editor: Khaled Abo-el-Sooud

Copyright (C) 2020 Tingting Hu et al. This is an open access article distributed under the Creative Commons Attribution License, which permits unrestricted use, distribution, and reproduction in any medium, provided the original work is properly cited.

\begin{abstract}
Autism spectrum disorders (ASDs) are a kind of neurodevelopmental disorder with rapidly increasing morbidity. In recent years, many studies have proposed a possible link between ASD and multiple environmental as well as genetic risk factors; nevertheless, recent studies have still failed to identify the specific pathogenesis. An analysis of the literature showed that oxidative stress and redox imbalance caused by high levels of reactive oxygen species (ROS) are thought to be integral parts of ASD pathophysiology. On the one hand, this review aims to elucidate the communications between oxidative stress, as a risk factor, and ASD. As such, there is also evidence to suggest that early assessment and treatment of antioxidant status are likely to result in improved long-term prognosis by disturbing oxidative stress in the brain to avoid additional irreversible brain damage. Accordingly, we will also discuss the possibility of novel therapies regarding oxidative stress as a target according to recent literature. On the other hand, this review suggests a definite relationship between ASD and an unbalanced gastrointestinal tract (GIT) microbiota (i.e., GIT dysbiosis). A variety of studies have concluded that the intestinal microbiota influences many aspects of human health, including metabolism, the immune and nervous systems, and the mucosal barrier. Additionally, the oxidative stress and GIT dysfunction in autistic children have both been reported to be related to mitochondrial dysfunction. What is the connection between them? Moreover, specific changes in the GIT microbiota are clearly observed in most autistic children, and the related mechanisms and the connection among ASD, the GIT microbiota, and oxidative stress are also discussed, providing a theory and molecular strategies for clinical practice as well as further studies.
\end{abstract}

\section{Introduction}

ASD, a loose umbrella term that includes a series of life-long heterogeneous clusters of neurodevelopmental disorders, is characterized by stereotyped behavior and deficits in social communication, interaction, and perception [1]. It is well documented that ASD occurs in all racial, ethnic, and socioeconomic groups. Last updated on July 11, 2016, the US Centers for Disease Control and Prevention (CDC https:// www.cdc.gov/) reported an incidence of 1 in 54 children worldwide; in addition, studies in Asia, Europe, and North America have identified individuals with ASD and shown an average prevalence of between $1 \%$ and $2 \%$ (see Table 1). Additionally, it is conservatively estimated that the preva- lence of ASD in China is $1 \%$, among which more than 2 million children aged 0-14 years have the disease [2]. Undoubtedly, ASD, considered a hidden disability, creates an enormous burden on individuals, families, and society [3]. Regrettably, there is no practical and targeted treatment for ASD, which has become a major worldwide health problem [4].

Although the causes of ASD remain unclear, many studies have pointed to the possible link between ASD and multiple environmental as well as genetic risk factors [5]. Of note, much evidence indicates that oxidative stress plays a vital role in the pathophysiology of nervous and mental diseases, particularly in ASD [6-9]. Anecdotal reports have suggested that oxidative stress response is crucially important 
TABLE 1: Summary of the Prevalence of ASD in different areas.

\begin{tabular}{|c|c|c|c|c|c|}
\hline Country & $\begin{array}{l}\text { Age range } \\
\text { studied }\end{array}$ & $\begin{array}{l}\text { Number of children in } \\
\text { population }\end{array}$ & Criteria used & Methodology used & $\begin{array}{l}\text { ASD prevalence } \\
\text { (CI) }\end{array}$ \\
\hline USA & 8 & 346,978 & DSM-IV & Case enumeration and record review & $14.6(8.2-24.6)$ \\
\hline Faroe Islands & 7 to 16 & 7122 & $\begin{array}{l}\text { DSM-IV } \\
\text { ICD-10 }\end{array}$ & Screening and direct exam & 5.6 \\
\hline Denmark & N/A & 404,816 & DSM-IV & Case enumeration & $6.9(6.5-7.2)$ \\
\hline Oman & 0 to 14 & 798,913 & DSM-IV & Case enumeration & $0.1(0.1-0.2)$ \\
\hline Taiwan & 0 to 18 & 372,642 & ICD-9 & Case enumeration & 2.9 \\
\hline South Korea & 7 to 12 & 55,266 & DSM-IV & $\begin{array}{l}\text { Case enumeration from survey and } \\
\text { direct exam }\end{array}$ & $26.4(19.1-33.7)$ \\
\hline $\begin{array}{l}\text { Western } \\
\text { Australia }\end{array}$ & N/A & 152,060 & DSM-IV & Case enumeration & $5.1(4.7-5.5)$ \\
\hline
\end{tabular}

Note: data are from the US Center for Disease Control and Prevention (CDC https://www.cdc.gov/). N/A: not applicable, i.e., the lack of data in a form or table.

to the neuroinflammatory response, and in a sense, the neuroinflammatory response has always been regarded as one of the pathogenic factors of ASD [10]. A sibling control study by Shannon et al. suggested that autistic children are more susceptible to oxidative stress on account of an imbalance in glutathione levels inside or outside of cells and a decrease in glutathione (GSH) storage capacity [11].

In recent years, as research continues, the research focus of the intestinal microbiota has been rapidly shifting from the abundance and diversity of microbial members to functional aspects. A variety of studies have concluded that the GIT microbiota influences many aspects of human health, including metabolism, the immune and nervous systems, and the mucosal barrier. In addition, the intestinal microbial fermentation of dietary fibres and resistant starch produces shortchain fatty acids (SCFAs), especially butyrate, propionate, and acetate [12]. Notably, propionate can result in GIT metabolic disturbance, reversible behavioral and signalling changes, neuroinflammation, etc. [13]. Therefore, not surprisingly, increasing evidence supports that autistic children are more likely to experience problems related to GIT, including food allergies (FAs), dysbiosis, inflammatory bowel disease (IBD), and indigestion [14, 15]. The GIT dysfunction in autistic children is related to mitochondrial redox imbalance, i.e., mitochondrial dysfunction, and there is an interaction between oxidative stress and mitochondrial dysfunction [16, 17]. Additionally, some connections exist between these factors (see Figure 1). The specific associations are discussed below.

In this review, many aspects of the role of oxidative stress and GIT microbiota in ASD are described. Furthermore, we will discuss, in the context of the most recent literature, the connections among oxidative stress, ASD, and GIT microbiota. Finally, the possibility of oxidative stress and GIT microbiota as therapeutic targets will be discussed, which will provide theoretical basis and novel strategies for clinical practice and future studies.

\section{Oxidative Stress and ASD}

2.1. The Definition of Oxidative Stress and the Importance/Role of Reactive Oxygen Species (ROS). Oxidative stress, considered an out-of-balance state between antioxidants and antioxidants, could lead to the cellular damage caused by reactive ROS or reactive nitrogen species (RNS) [18]. ROS, a kind of signalling molecule, may contribute to cell viability and tissue oxygen metabolism or inhibit the expression of related genes, including antioxidants $[19,20]$. When the level of oxidation exceeds the antioxidant defenses, oxidative stress occurs; in addition, different conditions may result in different levels of oxidative stress $[21,22]$. On the one hand, when ROS levels are relatively low, cells can appropriately respond to oxidative stress, a condition called "mild oxidative stress" or eustress. On the other hand, the condition that is more reactive to oxidative stress is termed distress, which is reported to be one of the principal causes of neuroinflammation and damage to astrocyte crosstalk resulting in ASD [23, 24].

In light of published references, under normal circumstances, there is a dynamic balance between the production of ROS and the antioxidant capacity of cells [25]. Furthermore, ROS are intermediate products and by-products that are produced in the electron transport in mitochondria [26, 27]. Notably, many enzymes, including superoxide dismutase (SOD) and glutathione peroxidase (GPx), have a high ROS scavenging capacity [8]. However, the specific role of ROS in ASD is still far from understood.

2.2. Blood Oxidative Stress Markers in Autistic Children. An increasing amount of evidence has shown that the pathogenesis of ASD is related to the accumulation of oxidized products and the disorder of antioxidant metabolism [28-30]. The role of oxidative stress in the development of ASD has been studied for decades, and a very large number of markers, as revealed by comparing blood levels of oxidative stress markers in autistic patients to those of healthy individuals, have been the focal point of clinical practice (see Table 2) [31-38]. As shown, the blood levels of oxidative stress markers were all decreased or increased to varying degrees in autistic patients compared with healthy controls, indicating that these markers may be used not only to diagnose ASD but also to provide indicators to monitor and guide individual therapy in the clinic [28]. However, the ability to implement these measures as soon as possible is still far from 


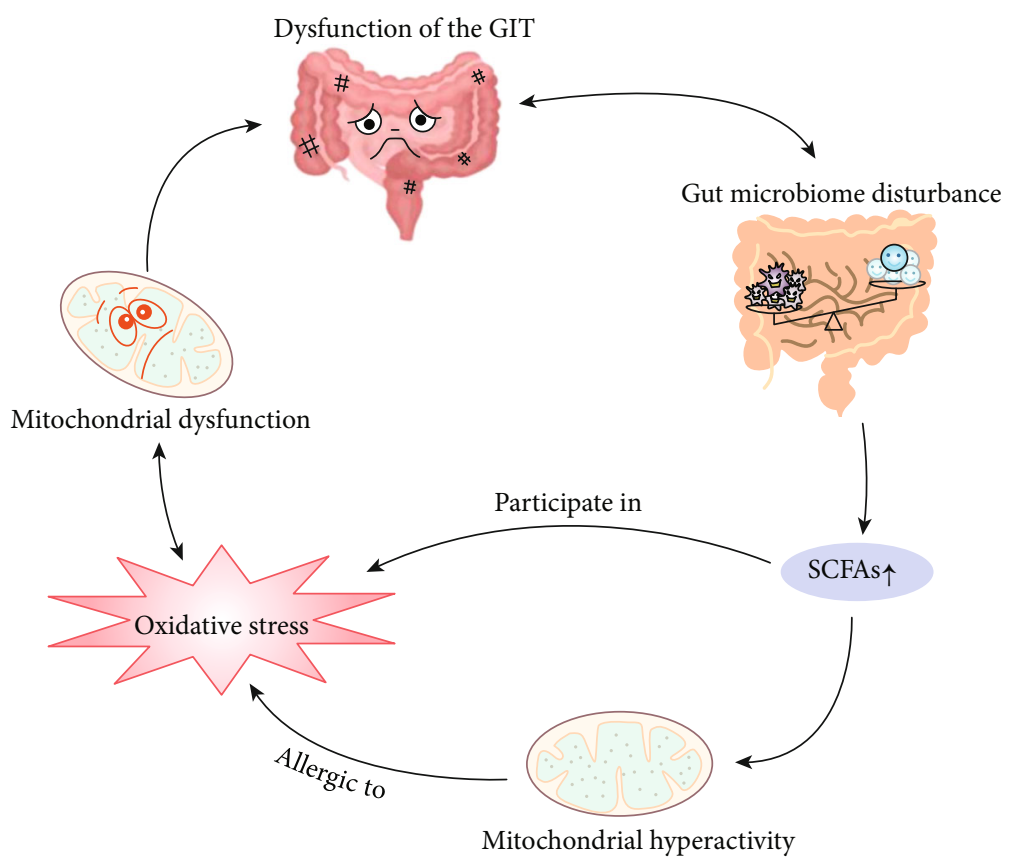

FIGURE 1: The connections among oxidative stress, mitochondrial dysfunction, and dysfunction of GIT in autistic children. The dysfunction of GIT in autistic children is related to mitochondrial dysfunction, and there is an interaction between oxidative stress and mitochondrial dysfunction. SCFAs, metabolites of the GIT microbiota, not only participate in the reaction process of oxidative stress but also can result in mitochondrial hyperactivity and further make mitochondria allergic to the oxidative stress.

TABLE 2: Blood levels of oxidative stress markers in autistic patients.

\begin{tabular}{|c|c|c|c|c|c|}
\hline \multirow{2}{*}{ Marker/specimen } & \multirow{2}{*}{ Units } & \multicolumn{2}{|c|}{ Values ASD } & \multirow{2}{*}{$p$ value } & \multirow{2}{*}{ Reference } \\
\hline & & Autistic children & Controls & & \\
\hline $\begin{array}{l}\text { Lipid hydroperoxide }(\mathrm{LOOH}) \text { in the temporal } \\
\text { cortex }\end{array}$ & $\mathrm{mmol} / \mathrm{mg}$ protein & About $21^{\#}$ & About $15^{\#}$ & $<0.05$ & {$[31]$} \\
\hline Plasma malondialdehyde (MDA) & $\mathrm{nmol} / \mathrm{mL}($ mean $\pm \mathrm{SD})$ & $4.16 \pm 1.67$ & $1.49 \pm 0.58$ & $<0.001$ & {$[32]$} \\
\hline Serum malondialdehyde (MDA) & $\mathrm{nmol} / \mathrm{mL}($ mean $\pm \mathrm{SD})$ & $8.6 \pm 0.5$ & $1.76 \pm 0.33$ & $\leq 0.001$ & {$[33]$} \\
\hline $\begin{array}{l}\text { RBC thiobarbituric acid reactive substances } \\
\text { (TBARS) }\end{array}$ & $\begin{array}{l}\mathrm{mmol} / \mathrm{g} \mathrm{Hb} \\
(\mathrm{mean} \pm \mathrm{SD})\end{array}$ & $0.032 \pm 0.0077$ & $0.015 \pm 0.0033$ & $<0.001$ & {$[32]$} \\
\hline Plasma protein carbonyl & $\mathrm{nmol} / \mathrm{mL}($ mean $\pm \mathrm{SD})$ & $4.202 \pm 0.3912$ & $2.256 \pm 0.148$ & $\begin{array}{c}< \\
0.0001\end{array}$ & {$[34]$} \\
\hline Serum $8 \mathrm{OHdG}$ & $\mathrm{ng} / \mathrm{mL}($ mean $\pm \mathrm{SD})$ & $13.134 \pm 1.33$ & $1.46 \pm 0.326$ & $\leq 0.001$ & {$[33]$} \\
\hline Plasma glutathione peroxidase (GPx) & $\mathrm{U} / \mathrm{L}($ mean $\pm \mathrm{SD})$ & $40.9 \pm 11.3$ & 24.2 & $\begin{array}{c}< \\
0.0001\end{array}$ & {$[35]$} \\
\hline Serum catalase (CAT) & $\mathrm{UAE} / \mathrm{L}($ mean $\pm \mathrm{SD})$ & $2.836 \pm 0.479$ & $0.689 \pm 0.157$ & $\leq 0.001$ & {$[33]$} \\
\hline RBC catalase $(\mathrm{CAT})$ & k/g Hb (mean \pm SD) & $209.31 \pm 61.92$ & $515.77 \pm 127.9$ & $<0.001$ & {$[32]$} \\
\hline RBC superoxide dismutase (SOD) & $\mathrm{U} / \mathrm{g} \mathrm{Hb}($ mean $\pm \mathrm{SD})$ & $2123.59 \pm 543.53$ & $971.31 \pm 239.14$ & $<0.001$ & {$[32]$} \\
\hline Plasma reduced glutathione (GSH) & $\mu \mathrm{mol} / \mathrm{L}($ mean $\pm \mathrm{SD})$ & $3.1 \pm 0.53$ & $4.2 \pm 0.72$ & $\begin{array}{c}< \\
0.0001\end{array}$ & {$[36]$} \\
\hline Plasma glutathione (GSH) & $\mu \mathrm{mol} / \mathrm{L}($ mean $\pm \mathrm{SD})$ & $3.14 \pm 0.56$ & $4.2 \pm 0.72$ & $\begin{array}{c}< \\
0.0001\end{array}$ & {$[37]$} \\
\hline Plasma oxidized glutathione (GSSG) & $\mathrm{nmol} / \mathrm{L}($ mean $\pm \mathrm{SD})$ & $0.48 \pm 0.16$ & $0.35 \pm 0.05$ & $<0.001$ & {$[37]$} \\
\hline MT-1A expression in blood & $\mathrm{N} / \mathrm{A}$ & $\begin{array}{l}\text { Higher (no data } \\
\text { available) }\end{array}$ & $\mathrm{N} / \mathrm{A}$ & $\leq 0.001$ & {$[38]$} \\
\hline
\end{tabular}

Note: the data are from references 31-38. RBC: C red blood cell; SD: standard deviation. ${ }^{\#}$ Values were estimated from the figure. N/A: not applicable, i.e., the lack of data in a form or table. 


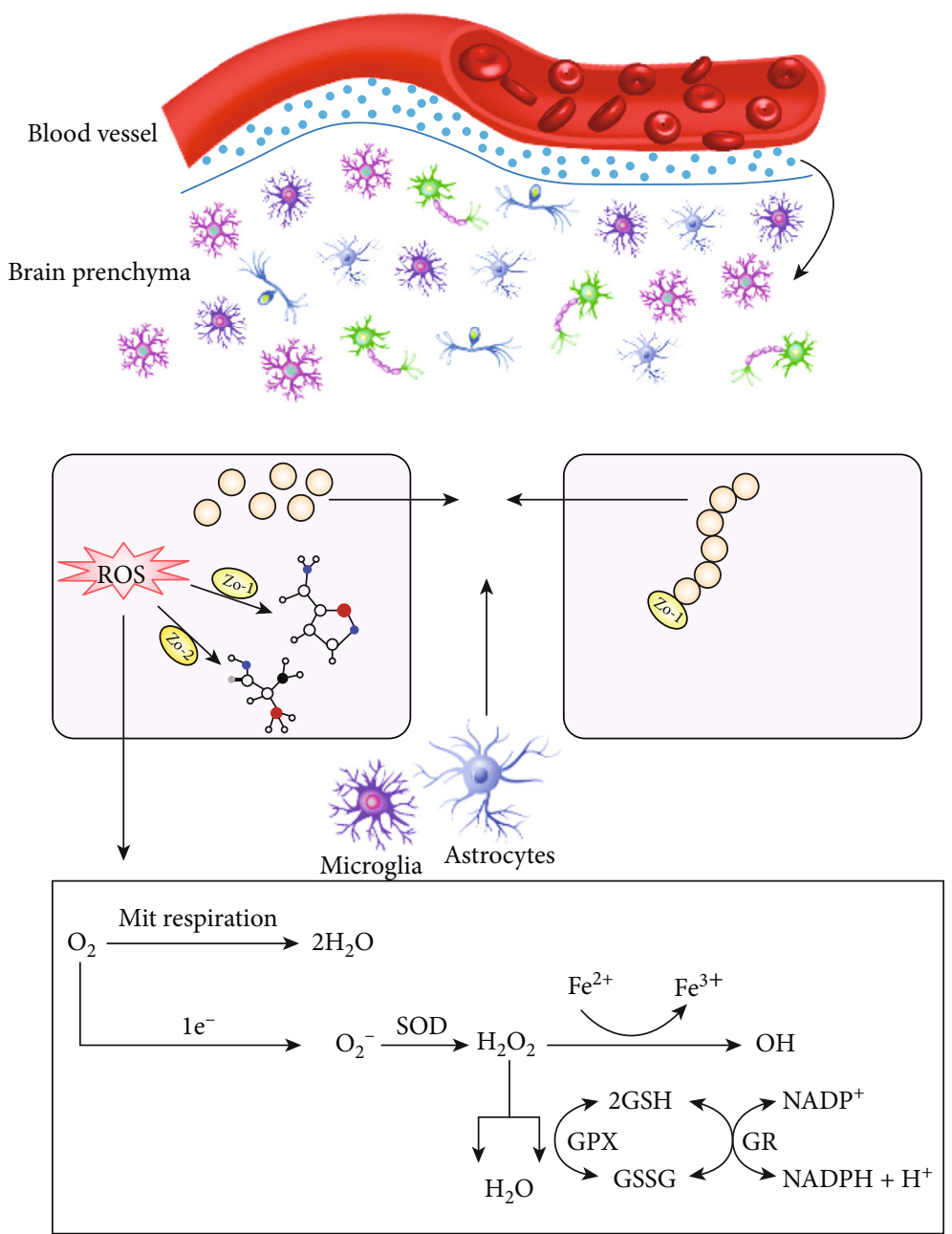

FIGURE 2: Schematic representation of oxidative stress in the brain.

fully accomplished and requires further insightful evidence, clinical reports, and research studies.

\subsection{Oxidative Stress in the Brain of Autistic Children. It is well} documented that oxidative stress is a primary potential cause of neuroinflammatory disorders and damage to the bloodbrain barrier (BBB), a highly selective boundary that separates circulating blood from the brain and extracellular fluid from the central nervous system (CNS) [39-41]. In healthy individuals, the $\mathrm{BBB}$ is formed by tight junctions between tight junction proteins and the endothelial cells of adjacent brain capillaries; then, the tight junction proteins are fixed in the endothelial cells by scaffolding proteins such as ZO-1 and ZO-2 [42]. When oxidative stress occurs in endothelial cells in autistic children, the BBB may be damaged, resulting in varied diffusion and transport [43]. Under normal conditions, ROS from various sources, including mitochondria, microglia, and astrocytes, accumulate. When excessive ROS are not properly scavenged, tight junctions can be altered, leading to further oxidative stress (see Figure 2) [44]. To combat this condition, some mechanisms are required to detoxify or neutralize the oxygen/nitrogen free radicals in the cell (see Figure 2). Devasagayam et al. found that super- oxide $\left(\mathrm{O}_{2}{ }^{-}\right)$could be produced as a by-product of normal metabolism; nevertheless, its accumulation may lead to the injury of cell structures and subsequently to oxidative stress [45]. As a result, superoxide enzymes called superoxide dismutase (SODs) immediately convert superoxide to hydrogen peroxide $\left(\mathrm{H}_{2} \mathrm{O}_{2}\right)$. Moreover, $\mathrm{H}_{2} \mathrm{O}_{2}$ is likely to be toxic to the cells as it can pass through cell membranes, thus damaging DNA. For this reason, scavenging hydrogen peroxide can be a target to disturb oxidative stress and may be a therapeutic intervention for ASD $[46,47]$. According to the study by Popa et al., catalase and GPx are considered the most vital enzymes that have the ability to convert $\mathrm{H}_{2} \mathrm{O}_{2}$ to $\mathrm{H}_{2} \mathrm{O}$. In addition, the tripeptide glutathione, an important antioxidant, plays a vital role in eliminating ROS [46]. Under a reaction catalysed by glutathione peroxidase (GPx), glutathione provides an electron to $\mathrm{H}_{2} \mathrm{O}_{2}$ and is then converted to an oxidized state. By making use of NAD (P) $\mathrm{H}$ as the electron donor, glutathione (GSH) could be reproduced again by glutathione reductase. Additionally, glutathione can also obliterate toxic substances from the cells in its role as a cofactor for GSH transferase $[46,48]$. In general, the brain is very sensitive to the accumulation of radicals such as ROS on account of the relatively weak protective mechanisms $[49,50]$. 


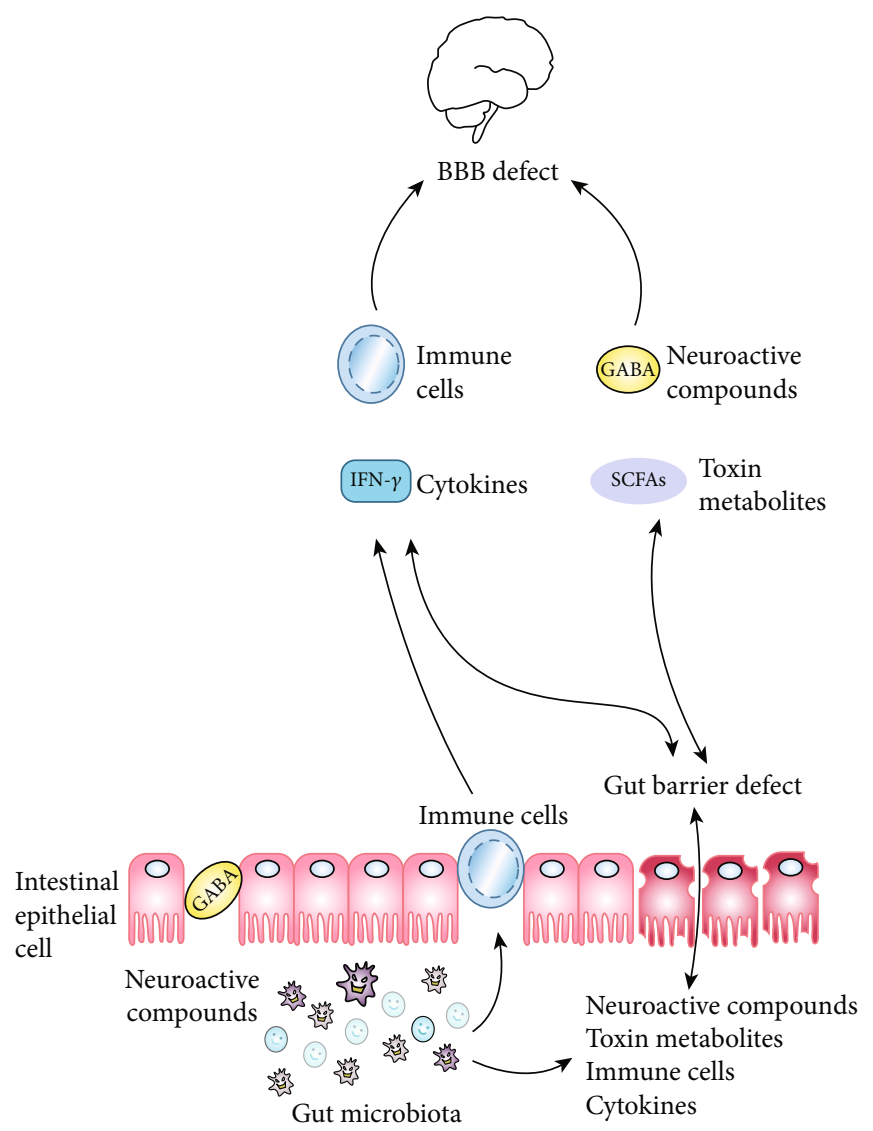

(a)

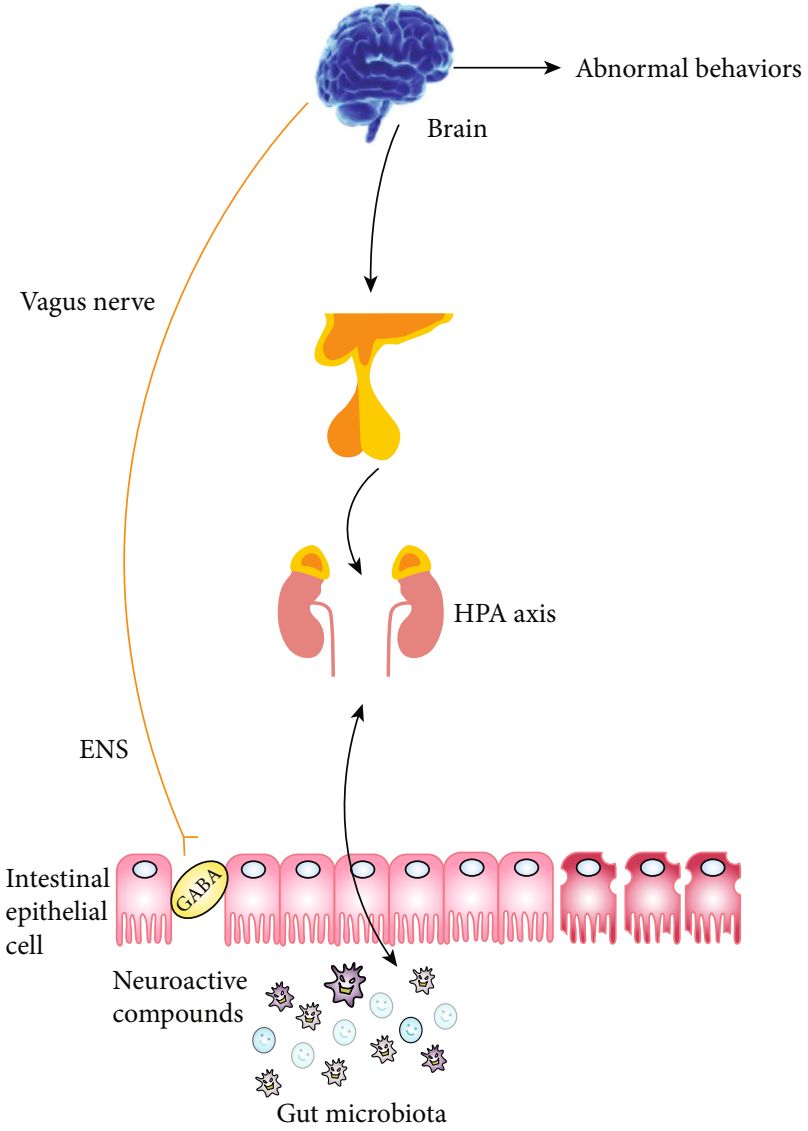

(b)

FIGURE 3: Relationships between the GIT microbiota and ASD (the microbiota-gut-brain-axis). Note: BBB: blood-brain barrier; ENS: enteric nervous system; GABA: $\gamma$-aminobutyric acid; HPA: hypothalamic-pituitary-adrenal; SCFAs: short-chain fatty acids.

\section{Gastrointestinal Tract (GIT) Microbiota and ASD}

3.1. GIT Microbiota and Factors That Affect the GIT Microbiota. In recent years, as research continues, the research focus of the GIT microbiota has been rapidly shifting from the abundance and diversity of the microbial members to functional aspects. A variety of studies have concluded that the intestinal microbiota influences many aspects of human health, including metabolism, the immune and nervous systems, and the mucosal barrier. The intestinal microbial fermentation of dietary fibres and resistant starch produces short-chain fatty acids (SCFAs), especially butyrate, propionate, and acetate [12]. Butyrate is a key energy substrate for colonocytes [51] and can drive the energy metabolism of colonocytes towards $\beta$-oxidation by stimulating PPAR- $\gamma$ signalling and limiting the luminal bioavailability of oxygen, maintaining homeostasis, and preventing gut microbiota dysbiosis [52]. Propionate regulates satiety signalling and gluconeogenesis in the liver, protecting the host from diet-induced obesity and associated glucose intolerance [53]. Other metabolites are produced by intestinal microbiota, and additional clinical evidence is needed to fully investigate their functions in physiology and pathophysiology. Examples include indole propionic acid, which seems to improve mucosal integrity in the gut [54], and ethylphenyl sulfate, which is connected to the exacerbation of autistic behaviour in a mouse model [55]. In addition, the intestinal microbiota has also been shown to have a positive impact on glycaemic control [56], energy homeostasis [57], lipid metabolism [58], and protein metabolism [59]. For the immune and nervous systems, the intestinal microbiota modulates the maturation and function of tissue-resident immune cells in the central nervous system (CNS), including microglia and astrocytes; they also influence the activation of peripheral immune cells, which regulate responses to neuroinflammation, brain injury, autoimmunity, and neurogenesis [60]. In addition, the healthy gut microbiota not only plays a dominant role in reinforcing the immunologic barrier [61] but also maintains the structural integrity of the intestinal mucosal barrier [62]. In summary, the GIT microbiota plays vital roles in human physiology and pathology.

As the GIT microbiota is a popular area in therapeutic research, several factors that contribute to the shaping of the normal GIT microbiota have been demonstrated. The mode of delivery (vaginal or caesarean), the local environment (i.e., mother and hospital), and the type of feeding (breast or formula) are significant factors that impact GIT microbiota composition during the neonatal period, resulting in changes that persist until infancy [63-65]. Age also 


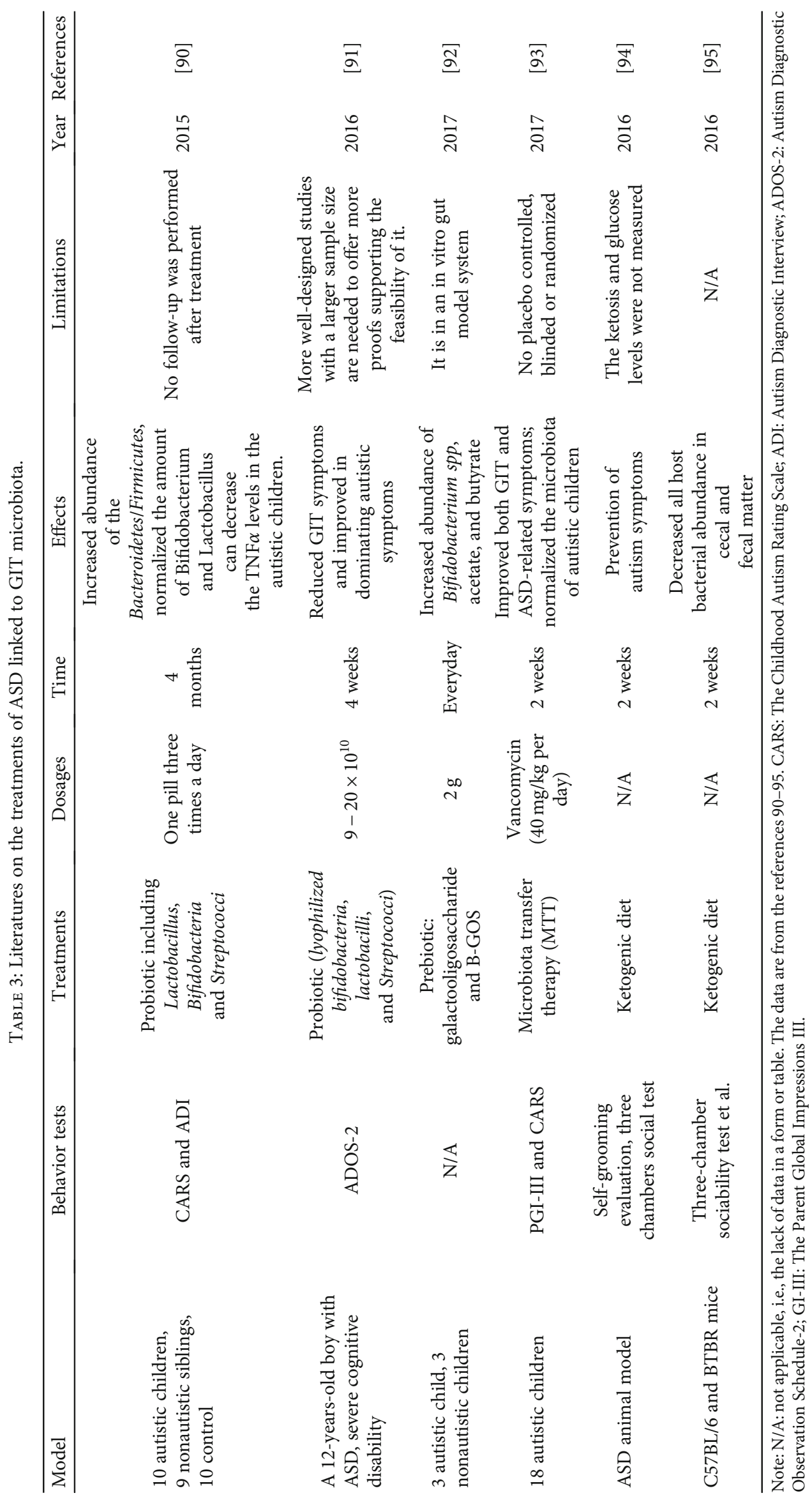



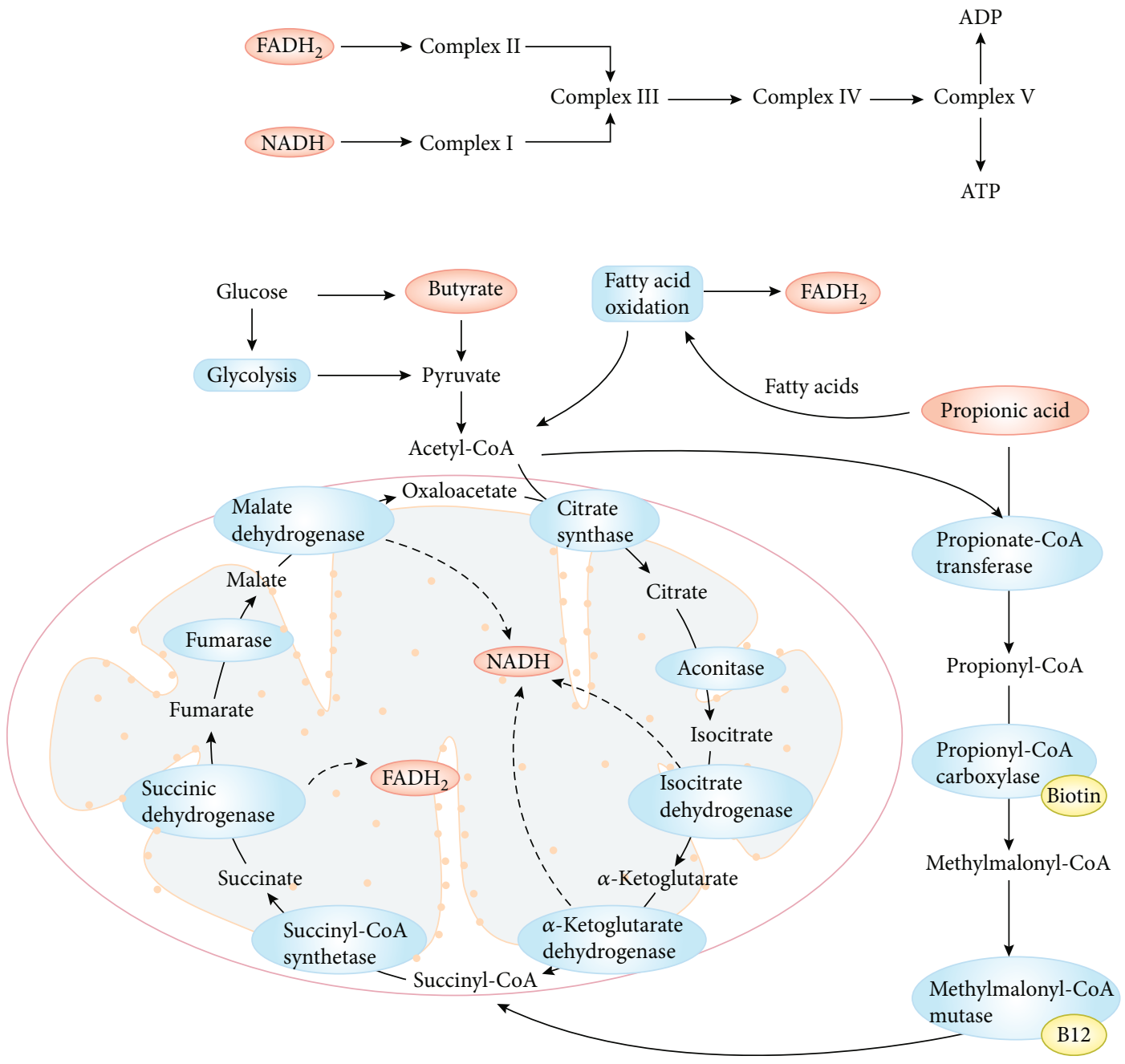

FIGURE 4: Mitochondrial pathways involved in SCFAs as substrates. There are two different starting points in the electron cycle chain, i.e., Complex I and Complex II, which have their exclusive fuel sources. Notedly, Complexes III, IV, and IV are all involved in the abovementioned reactions; furthermore, butyrate and propionic acid enter into mitochondria to participate in related reaction via two crossed and overlapped pathways. Butyrate which resembles the glucose commonly enters into the citric acid (TCA) cycle via Acetyl-CoA, a key reaction substance. The TCA cycle mainly generates a kind of substrate of Complex I called Nicotinamide adenine dinucleotide (NADH). FADH2, as the substrate of Complex II, can be massively produced in two varied metabolic pathways which propionic acid participates in. Equally, propionic acid can produce some substrates of oxidative stress such as SCFAs et al. to be involved in related responses.

plays an important role in shaping the gut microbiota. It is widely believed that mammals are first exposed to the microbiota in utero and that the microbiota expands rapidly after birth [66]. Studies have also shown that young children and adolescents have a significantly higher abundance of Clostridium and Bifidobacterium than adults $[67,68]$. Diet can also flexibly modulate gut microbiota composition. Just a four-day administration of entirely animal-based or plantbased diet is sufficient to lead to significant shifts in the human gut microbiota [69]. In general, the intake of a diet rich in fruits, vegetables, and fibres is associated with a higher richness and diversity of the gut microbiota [70]. While antibiotics are usually used for saving lives in the fight against infectious disease, many studies have shown their effect on gut bacterial ecology in recent years. The major changes in the GIT microbiota in response to antibiotics include diminished taxonomic diversity and persistence of the changes in a substantial proportion of individuals [71, 72]. In addition to the factors mentioned above, the gut microbiota configuration of individuals is affected by many other factors, including the genotype of the host, ethnicity, and sex [73-75].

3.2. Relationship between the GIT Microbiota and ASD. The study by Wang et al. showed that GIT symptoms, such as constipation (20\%) and diarrhoea (19\%), are more common in autistic children than in healthy children [76], similar to the results of meta-analyses by Coury et al. and McElhanon et al. [77, 78]. In addition, Buie et al. found that autistic children with GIT symptoms may display more apparent behavioral manifestations including anxiety, automatization, and aggression [79]. An increasing amount of evidence has shown that the GIT microbiota is directly or indirectly related to the symptoms of autistic children, mostly by affecting the mucosal immune system and human 
TABLE 4: The novel therapies of ASD regarding the oxidative stress as a target.

\begin{tabular}{|c|c|c|}
\hline Drugs & Pesticide effect & References \\
\hline Leukotrienes & $\begin{array}{c}\text { Inhibition of the expression or activity of 5-LOX; ameliorate neuroinflammation; } \\
\text { restore normal synaptic plasticity; } \\
\text { Improve learning and memory function in depressed rats }\end{array}$ & [105] \\
\hline Docosahexaenoic acid (DHA) & $\begin{array}{l}\text { Be good for the growth and development of the brain and effective at improving } \\
\text { cognitive function }\end{array}$ & {$[106]$} \\
\hline$\omega-3$ & $\begin{array}{l}\text { Be needed for the appropriate growth and development of the brain, proper synapse } \\
\text { formation, and to improve cognitive function }\end{array}$ & {$[107]$} \\
\hline Vit. B12 & Normalization of the Hcy level and amelioration of impaired lipid metabolism & {$[108]$} \\
\hline
\end{tabular}

Note: the information are from references 105-108.

metabolism $[3,80]$. According to a study on laboratory animals published online by the journal Cell, GIT barrier defects and GIT microbial disorder occur in mouse models of ASD; additionally, the abundance of Porphyromonadaceae, Prevotellaceae, Bacteroidales, and Lachnospiraceae in the offspring of mothers with maternal immune activation (MIA) was greater than that of the controls. Notably, the abundance of Ruminococcaceae, Erysipelotrichaceae, and Alcaligenaceae was greater in the controls [81]. The evidence shown by Finegold et al. demonstrates that the GIT microbiota of autistic children has a greater abundance of Lactobacillus, Clostridium, Bacteroidetes Desulfovibrio, Caloramator, and Sarcina as well as lower levels of Bifidobacterium and Firmicutes than the GIT microbiota of nonautistic children [82]. Furthermore, autistic children with GIT symptoms show lower levels of Prevotella, Coprococcus, and Veillonellaceae than autistic children without the abovementioned symptoms [83]. As stated, numerous studies have demonstrated the changes in the GIT microbiota of autistic children, but the relationship between GIT microbiota and ASD is relatively unexplored.

In recent years, as study continues, the microbiota-gutbrain-axis has been considered a bidirectional physiological communication between the brain, the GIT microbiota, and the GIT; not surprisingly, accumulating evidence demonstrates that this axis is related to the aetiology and pathogenesis of ASD [84-86]. As shown in Figures 3(a) and 3(b), the metabolites produced by the GIT microbiota, especially SCFAs, can pass through enterocytes (ECs) to have an impact on the function of the brain. In addition, some kinds of GIT microbiota can generate neuroactive substances such as 5HT and GABA, which can also pass through the EC, affect the function of the brain, and further lead to unexpected behaviors [87]. On the one hand, neuroactive substances, some GIT microbiota, and metabolic products could activate neurons in the brain and act on the function of the brain via vagus nerves. On the other hand, among the abovementioned substances, the neuroactive substances that directly affect the hypothalamic-pituitary-adrenal (HPA) axis can ultimately increase circulating levels of cortisol. Additionally, some GIT microbiota and metabolic products could also activate and induce GIT-immunizing cells to liberate cytokines (CKs) to play a corresponding role in the body's circulation $[88,89]$.

An increasing amount of evidence suggests that modulation of the GIT microbiota is a potential therapy in autistic children by elucidating the relationship between the
GIT microbiota and ASD, including faecal microbiota transplantation (FMT), probiotics, and dietotherapy. The literature on ASD treatments linked to the GIT microbiota in the past five years is summarized and analysed in Table 3 [90-95]. First, probiotics are considered to prevent intestinal diseases through functions such as regulating and controlling the blood-brain barrier (BBB) and gap-associated proteins [96]. The recently developed approach FMT is an intervention in which the faecal microorganisms from healthy persons are delivered to patients with bad GIT microbiota [97]. However, although many scholars and experts have speculated about the safety of FMT, but no final conclusions have been reached on this matter. Of course, the other abovementioned therapies also have their own limitations (see Table 3). In my opinion, additional well-designed studies with a larger sample size are needed to offer further evidence supporting the feasibility of these treatments.

\section{The Relationship among GIT Microbiota, Oxidative Stress, and ASD}

As discussed above, the relationship between GIT symptoms and ASD via mitochondrial dysfunction is quite convincing and worthy of study, as it is well documented that ASD is linked to GIT symptoms and mitochondrial dysfunction; additionally, the latter two are strongly related [98]. According to authoritative reports, the GIT, as an available site, can induce the production of SCFAs such as PPA and BUT [99]. Additionally, GIT dysfunction is observed in autistic children, such as the increased abundance of Clostridia spp., which produce PPA and BUT. There is no doubt that both PPA and BUT can regulate metabolism, including acting as mitochondrial fuels [100], despite entering into the mitochondrial energy pathways at slightly different sites (see Figure 4) [101]. In addition, SCFAs impair the physiological function of cells, resulting in further GIT symptoms related to ASD, including nonspecific inflammation [79, 93, 102].

To verify whether a connection among the GIT microbiota, oxidative stress, and ASD truly exists, Shannon et al. performed a blinded case-control study and unsurprisingly found differences in the function of mitochondria during several enzymatic reactions in autistic children compared to control children, indicating that differences actually exist in mitochondria rather than in certain enzymes. 
These researchers also found that the mitochondrial physiology of the GIT in autistic children differs from that in healthy children; notably, the discrepancies are particularly prominent in the caecum [17]. We speculate that autistic children might have different mitochondrial parameters, particularly in the caecum.

Mitochondria are characterized by energy generation; in addition, approximately $5 \%$ of autistic children exhibited impaired energy generation to make energy, and more than $30 \%$ of autistic children exhibit elevated biological markers. Therefore, we hypothesized that autistic children may have nontraditional mitochondrial diseases [103]. Similarly, a sibling control study found that lymphoblastoid cell lines (LCLs) from autistic children are active in the mitochondrial respiration process, which further leads to a greater sensitivity to oxidative stress [11]. Indeed, PPA and BUT are also abundant in the caecum, which indicates a role for the GIT microbiota in mitochondrial dysfunction in autistic children [104]. In general, the abovementioned correlated responses could result in a clearer understanding of the pathological relationship linked to GIT dysfunction and oxidative stress in ASD, which provides a theoretical basis as well as molecular strategies for new treatment paradigms.

\section{Novel Therapeutic Approaches for Oxidative Stress in ASD}

Based on the relationship discussed above, we will next discuss, in the context of the most recent literature, the possibility of novel therapies regarding oxidative stress as a target (Table 4) [105-108]. It is well documented that COX-2, as a vital enzyme that is overexpressed in tissues under oxidative stress, affects the metabolism of polyunsaturated acid (PUFA). $\omega-3$ is also considered to be connected with the high expression of COX-2. Leukotrienes are reported to decrease the expression or activity of an iron-containing dioxygenase named 5-LOX, ameliorating neuroinflammation, restoring normal synaptic plasticity, and improving learning ability and memory [11]. Additionally, docosahexaenoic acid (DHA) and $\omega-3$ are both needed for the appropriate growth and development of the brain, for proper synapse formation and to improve cognitive function [104, 105]. Notably, the use of vitamin B12 as a novel therapeutic approach that has recently aroused public attention has been shown to be used for the treatment of ASD; however, its efficacy is unclear [105].

\section{Concluding Remarks}

Many reports have highlighted the relationship among the GIT microbiota, oxidative stress, and ASD. A number of studies emphasize the important role of oxidative stress, which is connected to mitochondrial dysfunction, GIT microbiota disturbance, and thus the production of various metabolites. This review has summarized the latest research on the related mechanisms, but most of the authors have only concentrated on individual pathogenic mechanisms or metabolites; thus, there is an urgent need for studies considering broader biochemical pathways. Additionally, among all the novel ASD therapies mentioned above, the potential use- fulness of most have been investigated. Although the results are promising, these therapies are still thought to have limitations and lack safety testing. In general, the author thinks that additional well-designed studies with a larger sample size are needed to offer further evidence supporting the feasibility of these treatments. In addition, the appropriate dose and timing of therapy also require further study.

\section{Conflicts of Interest}

The authors declare no conflict of interest.

\section{Authors' Contributions}

TH drafted the manuscript, YD generated the figure, $\mathrm{CH}$ and YD performed the background research, and $\mathrm{MZ}$ and $\mathrm{QH}$ edited the manuscript. All authors have read and approved the content of the manuscript. Tingting $\mathrm{Hu}$ and Yinmiao Dong contributed equally to this study.

\section{Acknowledgments}

This study was supported by grants from the Hunan Innovative Provincial Construction Project (2019SK2211) and Changsha Science and Technology Plan Project (kq2001044).

\section{References}

[1] J. Baio, L. Wiggins, D. L. Christensen et al., "Prevalence of autism Spectrum disorder among children aged 8 years-autism and developmental disabilities monitoring network, 11 sites, United States, 2014," MMWR Surveillance Summaries, vol. 67 , no. 6, pp. 1-23, 2018.

[2] C. Wu, Autism Research Institute. Report on the Development of China's Autism Education and Rehabilitation Industry (in Chinese). II, Huaxia Publishing House, Beijing, 2017.

[3] M. De Angelis, R. Francavilla, M. Piccolo, A. De Giacomo, and M. Gobbetti, "Autism spectrum disorders and intestinal microbiota," Gut Microbes, vol. 6, no. 3, pp. 207-213, 2015.

[4] L. F. Eichenfield, J. M. Hanifin, L. A. Beck et al., "Atopic dermatitis and asthma: parallels in the evolution of treatment," Pediatrics, vol. 111, no. 3, pp. 608-616, 2003.

[5] K. Saad, A. A. Abdel-rahman, Y. M. Elserogy et al., "Vitamin $D$ status in autism spectrum disorders and the efficacy of vitamin D supplementation in autistic children," Nutritional Neuroscience, vol. 19, no. 8, pp. 346-351, 2015.

[6] A. Nadeem, S. F. Ahmad, S. M. Attia, L. Y. al-Ayadhi, N. O. alHarbi, and S. A. Bakheet, "Dysregulated enzymatic antioxidant network in peripheral neutrophils and monocytes in children with autism," Progress in Neuro-Psychopharmacology \& Biological Psychiatry, vol. 88, pp. 352-359, 2019.

[7] A. Messina, V. Monda, F. Sessa et al., "Sympathetic, metabolic adaptations, and oxidative stress in autism Spectrum disorders: how far from physiology?," Frontiers in Physiology, vol. 9, pp. 261-277, 2018.

[8] M. Fransen, M. Nordgren, B. Wang, and O. Apanasets, "Role of peroxisomes in ROS/RNS-metabolism: implications for human disease," Biochimica et Biophysica Acta, vol. 1822, no. 9, pp. 1363-1373, 2012. 
[9] C. M. Cipolla and I. J. Lodhi, "Peroxisomal dysfunction in age-related diseases," Trends in Endocrinology and Metabolism, vol. 28, no. 4, pp. 297-308, 2017.

[10] G. Bjørklund, N. A. Meguid, M. A. El-Bana et al., "Oxidative stress in autism spectrum disorder," Molecular Neurobiology, vol. 57, no. 5, pp. 2314-2332, 2020.

[11] S. Rose, S. C. Bennuri, R. Wynne, S. Melnyk, S. J. James, and R. E. Frye, "Mitochondrial and redox abnormalities in autism lymphoblastoid cells: a sibling control study," The FASEB Journal, vol. 31, no. 3, pp. 904-909, 2017.

[12] J. Hu, S. Lin, B. Zheng, and P. C. K. Cheung, "Short-chain fatty acids in control of energy metabolism," Critical Reviews in Food Science and Nutrition, vol. 58, no. 8, pp. 1243-1249, 2018.

[13] D. F. MacFabe, "Enteric short-chain fatty acids: microbial messengers of metabolism, mitochondria, and mind: implications in autism spectrum disorders," Microbial Ecology in Health and Disease, vol. 26, p. 28177, 2015.

[14] M. Codina-Solà, B. Rodríguez-Santiago, A. Homs et al., "Integrated analysis of whole-exome sequencing and transcriptome profiling in males with autism spectrum disorders," Molecular Autism, vol. 6, no. 1, pp. 21-27, 2015.

[15] C. P. Lazaro, M. P. Ponde, and L. E. Rodrigues, "Opioid peptides and gastrointestinal symptoms in autism spectrum disorders," Revista Brasileira de Psiquiatria, vol. 38, no. 3, pp. 243-246, 2016.

[16] D. W. Kang, Z. E. Ilhan, N. G. Isern et al., "Differences in fecal microbial metabolites and microbiota of children with autism spectrum disorders," Anaerobe, vol. 49, pp. 121-131, 2018.

[17] S. Rose, S. C. Bennuri, K. F. Murray, T. Buie, H. Winter, and R. E. Frye, "Mitochondrial dysfunction in the gastrointestinal mucosa of children with autism: a blinded case-control study," PLoS One, vol. 12, no. 10, article e0186377, 2017.

[18] S. Chirumbolo and G. Bjorklund, "PERM hypothesis: the fundamental machinery able to elucidate the role of xenobiotics and hormesis in cell survival and homeostasis," International Journal of Molecular Sciences, vol. 18, no. 1, pp. p165p171, 2017.

[19] Q. Guo, F. Li, Y. Duan et al., "Oxidative stress, nutritional antioxidants and beyond," Science China. Life Sciences, vol. 63, no. 6, pp. 866-874, 2020.

[20] V. Chevallier, M. R. Andersen, and L. Malphettes, “Oxidative stress-alleviating strategies to improve recombinant protein production in CHO cells," Biotechnology and Bioengineering, vol. 117, no. 4, pp. 1172-1186, 2020.

[21] M. Costanzo, F. Boschi, F. Carton et al., "Low ozone concentrations promote adipogenesis in human adipose-derived adult stem cells," European Journal of Histochemistry, vol. 62, no. 3, pp. p2969-p2975, 2018.

[22] M. T. Islam, "Oxidative stress and mitochondrial dysfunction-linked neurodegenerative disorders," Neurological Research, vol. 39, no. 1, pp. 73-82, 2017.

[23] A. El-Ansary, G. Bjørklund, A. M. Khemakhem, L. AlAyadhi, S. Chirumbolo, and A. B. Bacha, "Metabolism-associated markers and childhood autism rating scales (CARS) as a measure of autism severity," Journal of Molecular Neuroscience, vol. 65, no. 3, pp. 265-276, 2018.

[24] F. B. Russo, B. C. Freitas, G. C. Pignatari et al., "Modeling the interplay between neurons and astrocytes in autism using human induced pluripotent stem cells," Biological Psychiatry, vol. 83, no. 7, pp. 569-578, 2018.
[25] P. Newsholme, V. F. Cruzat, K. N. Keane, R. Carlessi, and P. I. H. de Bittencourt Jr., "Molecular mechanisms of ROS production and oxidative stress in diabetes," The Biochemical Journal, vol. 473, no. 24, pp. 4527-4550, 2016.

[26] R. Hameister, C. Kaur, S. T. Dheen, C. H. Lohmann, and G. Singh, "Reactive oxygen/nitrogen species (ROS/RNS) and oxidative stress in arthroplasty," Journal of Biomedical Materials Research. Part B, Applied Biomaterials, vol. 108, no. 5, pp. 2073-2087, 2020.

[27] C. Kim, "ROS-driven oxidative modification: its impact on chloroplasts-nucleus communication," Frontiers in Plant Science, vol. 10, pp. 1729-1735, 2019.

[28] A. Frustaci, M. Neri, A. Cesario et al., "Oxidative stressrelated biomarkers in autism: systematic review and metaanalyses," Free Radical Biology \& Medicine, vol. 52, no. 10, pp. 2128-2141, 2012.

[29] L. J. Raymond, R. C. Deth, and N. V. Ralston, "Potential role of selenoenzymes and antioxidant metabolism in relation to autism etiology and pathology," Autism Research and Treatment, vol. 2014, Article ID 164938, 15 pages, 2014.

[30] G. Bjørklund, N. A. Meguid, A. El-Ansary et al., "Diagnostic and severity-tracking biomarkers for autism spectrum disorder," Journal of Molecular Neuroscience, vol. 66, no. 4, pp. 492-511, 2018.

[31] A. Chauhan, F. Gu, M. M. Essa et al., "Brain region-specific deficit in mitochondrial electron transport chain complexes in children with autism," Journal of Neurochemistry, vol. 117, no. 2, pp. 209-220, 2011.

[32] S. S. Zoroglu, F. Armutcu, S. Ozen et al., "Increased oxidative stress and altered activities of erythrocyte free radical scavenging enzymes in autism," European Archives of Psychiatry and Clinical Neuroscience, vol. 254, no. 3, pp. 143-147, 2004.

[33] S. Faber, G. M. Zinn, A. Boggess, T. Fahrenholz, J. C. Kern II, and H. M. S. Kingston, "A cleanroom sleeping environment's impact on markers of oxidative stress, immune dysregulation, and behavior in children with autism spectrum disorders," BMC Complementary and Alternative Medicine, vol. 15, no. 1, pp. 71-77, 2015.

[34] M. M. Essa, G. J. Guillemin, M. I. Waly et al., "Increased markers of oxidative stress in autistic children of the Sultanate of Oman," Biological Trace Element Research, vol. 147, no. 1-3, pp. 25-27, 2012.

[35] S. Söğüt, S. S. Zoroğlu, H. Özyurt et al., "Changes in nitric oxide levels and antioxidant enzyme activities may have a role in the pathophysiological mechanisms involved in autism," Clinica Chimica Acta, vol. 331, no. 1-2, pp. 111-117, 2003.

[36] D. A. Geier, J. K. Kern, C. R. Garver et al., "Biomarkers of environmental toxicity and susceptibility in autism," Journal of the Neurological Sciences, vol. 280, no. 1-2, pp. 101-108, 2009.

[37] D. A. Geier, J. K. Kern, C. R. Garver, J. B. Adams, T. Audhya, and M. R. Geier, "A prospective study of transsulfuration biomarkers in autistic disorders," Neurochemical Research, vol. 34, no. 2, pp. 386-393, 2009.

[38] M. Pintaudi, E. Veneselli, A. Voci et al., "Blood oxidative stress and metallothionein expression in Rett syndrome: probing for markers," The World Journal of Biological Psychiatry, vol. 17, no. 3, pp. 198-209, 2015.

[39] R. Daneman and A. Prat, "The blood-brain barrier," Cold Spring Harbor Perspectives in Biology, vol. 7, no. 1, p. a020412, 2015. 
[40] Y. Serlin, I. Shelef, B. Knyazer, and A. Friedman, "Anatomy and physiology of the blood-brain barrier," Seminars in Cell \& Developmental Biology, vol. 38, pp. 2-6, 2015.

[41] S. G. Patching, "Glucose transporters at the blood-brain barrier: function, regulation and gateways for drug delivery," Molecular Neurobiology, vol. 54, no. 2, pp. 1046-1077, 2017.

[42] H. Jyonouchi, L. Geng, S. Rose, S. C. Bennuri, and R. E. Frye, "Variations in mitochondrial respiration differ in IL-1ss/IL10 ratio based subgroups in autism spectrum disorders," Frontiers in Psychiatry, vol. 10, pp. 71-75, 2019.

[43] J. H. Ellwanger, S. I. R. Franke, D. L. Bordin, D. Prá, and J. A. P. Henriques, "Biological functions of selenium and its potential influence on Parkinson's disease," Anais da Academia Brasileira de Ciências, vol. 88, Supplement 3, pp. 16551674, 2016.

[44] E. Georgieva, D. Ivanova, Z. Zhelev, R. Bakalova, M. Gulubova, and I. Aoki, "Mitochondrial dysfunction and redox imbalance as a diagnostic marker of "free radical diseases"," Anticancer Research, vol. 37, no. 10, pp. 5373-5381, 2017.

[45] T. P. A. Devasagayam, J. C. Tilak, K. K. Boloor, K. S. Sane, S. S. Ghaskadbi, and R. D. Lele, "Free radicals and antioxidants in human health: current status and future prospects," The Journal of the Association of Physicians of India, vol. 52, pp. 794-804, 2004.

[46] A. Popa-Wagner, S. Mitran, S. Sivanesan, E. Chang, and A.M. Buga, "ROS and brain diseases: the good, the bad, and the ugly," Oxidative Medicine and Cellular Longevity, vol. 2013, Article ID 963520, 14 pages, 2013.

[47] L. Lavie, "Oxidative stress in obstructive sleep apnea and intermittent hypoxia-revisited-the bad ugly and good: implications to the heart and brain," Sleep Medicine Reviews, vol. 20, pp. 27-45, 2015.

[48] K. Ohja, E. Gozal, M. Fahnestock et al., "Neuroimmunologic and neurotrophic interactions in autism spectrum disorders: relationship to neuroinflammation," Neuromolecular Medicine, vol. 20, no. 2, pp. 161-173, 2018.

[49] L. Pangrazzi, L. Balasco, and Y. Bozzi, "Oxidative stress and immune system dysfunction in autism spectrum disorders," International Journal of Molecular Sciences, vol. 21, no. 9, pp. 3293-3307, 2020.

[50] H. Ormstad, V. Bryn, O. D. Saugstad, O. Skjeldal, and M. Maes, "Role of the immune system in autism spectrum disorders (ASD)," CNS \& Neurological Disorders Drug Targets, vol. 17, no. 7, pp. 489-495, 2018.

[51] D. R. Donohoe, N. Garge, X. Zhang et al., "The microbiome and butyrate regulate energy metabolism and autophagy in the mammalian colon," Cell Metabolism, vol. 13, no. 5, pp. 517-526, 2011.

[52] M. X. Byndloss, E. E. Olsan, F. Rivera-Chávez et al., "Microbiota-activated PPAR- $\gamma$ signaling inhibits dysbiotic Enterobacteriaceae expansion," Science, vol. 357, no. 6351, pp. 570-575, 2017.

[53] F. De Vadder, P. Kovatcheva-Datchary, D. Goncalves et al., "Microbiota-generated metabolites promote metabolic benefits via gut-brain neural circuits," Cell, vol. 156, no. 1-2, pp. 84-96, 2014.

[54] S. L. Long, C. Gahan, and S. A. Joyce, "Interactions between gut bacteria and bile in health and disease," Molecular Aspects of Medicine, vol. 56, pp. 54-65, 2017.
[55] T. Li and J. Y. Chiang, "Bile acid signaling in metabolic disease and drug therapy," Pharmacological Reviews, vol. 66, no. 4, pp. 948-983, 2014.

[56] L. Brunkwall and M. Orho-Melander, "The gut microbiome as a target for prevention and treatment of hyperglycaemia in type 2 diabetes: from current human evidence to future possibilities," Diabetologia, vol. 60, no. 6, pp. 943-951, 2017.

[57] M. Rosenbaum, R. Knight, and R. L. Leibel, "The gut microbiota in human energy homeostasis and obesity," Trends in Endocrinology and Metabolism, vol. 26, no. 9, pp. 493-501, 2015.

[58] M. Schoeler and R. Caesar, "Dietary lipids, gut microbiota and lipid metabolism," Reviews in Endocrine \& Metabolic Disorders, vol. 20, no. 4, pp. 461-472, 2019.

[59] L. Madsen, L. S. Myrmel, E. Fjære, B. Liaset, and K. Kristiansen, "Links between dietary protein sources, the gut microbiota, and obesity," Frontiers in Physiology, vol. 8, pp. 1047-1061, 2017.

[60] T. C. Fung, C. A. Olson, and E. Y. Hsiao, "Interactions between the microbiota, immune and nervous systems in health and disease," Nature Neuroscience, vol. 20, no. 2, pp. 145-155, 2017.

[61] Y. Belkaid and T. W. Hand, "Role of the microbiota in immunity and inflammation," Cell, vol. 157, no. 1, pp. 121-141, 2014.

[62] C. Pellegrini, L. Antonioli, R. Colucci, C. Blandizzi, and M. Fornai, "Interplay among gut microbiota, intestinal mucosal barrier and enteric neuro-immune system: a common path to neurodegenerative diseases?," Acta Neuropathologica, vol. 136, no. 3, pp. 345-361, 2018.

[63] Y. Shao, S. C. Forster, E. Tsaliki et al., "Stunted microbiota and opportunistic pathogen colonization in caesareansection birth," Nature, vol. 574, no. 7776, pp. 117-121, 2019.

[64] M. F. Laursen, M. I. Bahl, K. F. Michaelsen, and T. R. Licht, "First foods and gut microbes," Frontiers in Microbiology, vol. 8, pp. 356-371, 2017.

[65] A. Fattorusso, L. di Genova, G. Dell'Isola, E. Mencaroni, and S. Esposito, "Autism spectrum disorders and the gut microbiota," Nutrients, vol. 11, no. 3, pp. 521-529, 2019.

[66] T. Gensollen, S. S. Iyer, D. L. Kasper, and R. S. Blumberg, "How colonization by microbiota in early life shapes the immune system," Science, vol. 352, no. 6285, pp. 539-544, 2016.

[67] R. Agans, L. Rigsbee, H. Kenche, S. Michail, H. J. Khamis, and O. Paliy, "Distal gut microbiota of adolescent children is different from that of adults," FEMS Microbiology Ecology, vol. 77, no. 2, pp. 404-412, 2011.

[68] T. Ringel-Kulka, J. Cheng, Y. Ringel et al., "Intestinal microbiota in healthy U.S. young children and adults-a high throughput microarray analysis," PLoS One, vol. 8, no. 5, article e64315, 2013.

[69] L. A. David, C. F. Maurice, R. N. Carmody et al., "Diet rapidly and reproducibly alters the human gut microbiome," Nature, vol. 505, no. 7484, pp. 559-563, 2014.

[70] S. M. Jandhyala, R. Talukdar, C. Subramanyam, H. Vuyyuru, M. Sasikala, and D. N. Reddy, "Role of the normal gut microbiota," World Journal of Gastroenterology, vol. 21, no. 29, pp. 8787-8803, 2015.

[71] S. Kim, A. Covington, and E. G. Pamer, "The intestinal microbiota: antibiotics, colonization resistance, and enteric 
pathogens," Immunological Reviews, vol. 279, no. 1, pp. 90105, 2017.

[72] S. Panda, I. el khader, F. Casellas et al., "Short-term effect of antibiotics on human gut microbiota," PLoS One, vol. 9, no. 4, article e95476, 2014.

[73] A. Kurilshikov, C. Wijmenga, J. Fu, and A. Zhernakova, "Host genetics and gut microbiome: challenges and perspectives," Trends in Immunology, vol. 38, no. 9, pp. 633-647, 2017.

[74] A. W. Brooks, S. Priya, R. Blekhman, and S. R. Bordenstein, "Gut microbiota diversity across ethnicities in the United States," PLoS Biology, vol. 16, no. 12, article e2006842, 2018.

[75] M. Insenser, M. Murri, R. del Campo, M. Á. Martínez-García, E. Fernández-Durán, and H. F. Escobar-Morreale, "Gut microbiota and the polycystic ovary syndrome: influence of sex, sex hormones, and obesity," The Journal of Clinical Endocrinology and Metabolism, vol. 103, no. 7, pp. 25522562,2018

[76] L. W. Wang, D. J. Tancredi, and D. W. Thomas, “The prevalence of gastrointestinal problems in children across the United States with autism spectrum disorders from families with multiple affected members," Journal of Developmental and Behavioral Pediatrics, vol. 32, no. 5, pp. 351-360, 2011.

[77] N. Connolly, J. Anixt, P. Manning, D. Ping-I Lin, K. A. Marsolo, and K. Bowers, "Maternal metabolic risk factors for autism spectrum disorder-an analysis of electronic medical records and linked birth data," Autism Research, vol. 9, no. 8, pp. 829-837, 2016.

[78] B. O. McElhanon, C. McCracken, S. Karpen, and W. G. Sharp, "Gastrointestinal symptoms in autism spectrum disorder: a meta-analysis,” Pediatrics, vol. 133, no. 5, pp. 872-883, 2014.

[79] T. Buie, G. J. Fuchs III, G. T. Furuta et al., "Recommendations for evaluation and treatment of common gastrointestinal problems in children with ASDs," Pediatrics, vol. 125, Supplement 1, pp. S19-S29, 2010.

[80] G. V. Shmarina, E. S. Ershova, N. V. Simashkova et al., "Oxidized cell-free DNA as a stress-signaling factor activating the chronic inflammatory process in patients with autism spectrum disorders," Journal of Neuroinflammation, vol. 17, no. 1, pp. 212-219, 2020.

[81] E. Y. Hsiao, S. W. McBride, S. Hsien et al., "Microbiota modulate behavioral and physiological abnormalities associated with neurodevelopmental disorders," Cell, vol. 155, no. 7, pp. 1451-1463, 2013.

[82] L. de Magistris, V. Familiari, A. Pascotto et al., "Alterations of the intestinal barrier in patients with autism spectrum disorders and in their first-degree relatives," Journal of Pediatric Gastroenterology and Nutrition, vol. 51, no. 4, pp. 418-424, 2010.

[83] D. W. Kang, J. G. Park, Z. E. Ilhan et al., "Reduced incidence of Prevotella and other fermenters in intestinal microflora of autistic children," PLoS One, vol. 8, no. 7, article e68322, 2013.

[84] P. Srikantha and M. H. Mohajeri, "The possible role of the microbiota-gut-brain-axis in autism spectrum disorder," International Journal of Molecular Sciences, vol. 20, no. 9, pp. 2115-2129, 2019.

[85] E. Santocchi, L. Guiducci, F. Fulceri et al., "Gut to brain interaction in Autism Spectrum Disorders: a randomized controlled trial on the role of probiotics on clinical, biochemical and neurophysiological parameters," BMC Psychiatry, vol. 16, no. 1, pp. 183-189, 2016.

[86] T. G. Dinan and J. F. Cryan, "Gut instincts: microbiota as a key regulator of brain development, ageing and neurodegeneration," The Journal of Physiology, vol. 595, no. 2, pp. 489503, 2017.

[87] Q. Li, Y. Han, A. B. C. Dy, and R. J. Hagerman, "The gut microbiota and autism spectrum disorders," Frontiers in Cellular Neuroscience, vol. 11, pp. 120-136, 2017.

[88] C. G. M. de Theije, H. Wopereis, M. Ramadan et al., "Altered gut microbiota and activity in a murine model of autism spectrum disorders," Brain, Behavior, and Immunity, vol. 37, pp. 197-206, 2014.

[89] S. A. Buffington, G. V. di Prisco, T. A. Auchtung, N. J. Ajami, J. F. Petrosino, and M. Costa-Mattioli, "Microbial reconstitution reverses maternal diet-induced social and synaptic deficits in offspring," Cell, vol. 165, no. 7, pp. 1762-1775, 2016.

[90] A. Tomova, V. Husarova, S. Lakatosova et al., "Gastrointestinal microbiota in children with autism in Slovakia," Physiology \& Behavior, vol. 138, pp. 179-187, 2015.

[91] E. Grossi, S. Melli, D. Dunca, and V. Terruzzi, "Unexpected improvement in core autism spectrum disorder symptoms after long-term treatment with probiotics," SAGE Open Medical Case Reports, vol. 4, 2016.

[92] R. Grimaldi, D. Cela, J. R. Swann et al., "In vitro fermentation of B-GOS: impact on faecal bacterial populations and metabolic activity in autistic and non-autistic children," FEMS Microbiology Ecology, vol. 93, no. 2, article fiw233, 2017.

[93] D. W. Kang, J. B. Adams, A. C. Gregory et al., "Microbiota Transfer Therapy alters gut ecosystem and improves gastrointestinal and autism symptoms: an open-label study," Microbiome, vol. 5, no. 1, pp. 10-24, 2017.

[94] K. Castro, D. Baronio, I. S. Perry, R. dos Santos Riesgo, and C. Gottfried, "The effect of ketogenic diet in an animal model of autism induced by prenatal exposure to valproic acid," Nutritional Neuroscience, vol. 20, no. 6, pp. 343-350, 2017.

[95] C. Newell, M. R. Bomhof, R. A. Reimer, D. S. Hittel, J. M. Rho, and J. Shearer, "Ketogenic diet modifies the gut microbiota in a murine model of autism spectrum disorder," Molecular Autism, vol. 7, no. 1, pp. 37-46, 2016.

[96] T. Yatsunenko, F. E. Rey, M. J. Manary et al., "Human gut microbiome viewed across age and geography," Nature, vol. 486, no. 7402, pp. 222-227, 2012.

[97] L. Wang, C. T. Christophersen, M. J. Sorich, J. P. Gerber, M. T. Angley, and M. A. Conlon, "Increased abundance of Sutterella spp. and Ruminococcus torques in feces of children with autism spectrum disorder," Molecular Autism, vol. 4, no. 1, pp. 42-51, 2013.

[98] R. E. Frye, S. Rose, J. Slattery, and D. F. MacFabe, "Gastrointestinal dysfunction in autism spectrum disorder: the role of the mitochondria and the enteric microbiome," Microbial Ecology in Health and Disease, vol. 26, p. 27458, 2015.

[99] B. B. Nankova, R. Agarwal, D. F. MacFabe, and E. F. la Gamma, "Enteric bacterial metabolites propionic and butyric acid modulate gene expression, including CREB-dependent catecholaminergic neurotransmission, in PC12 cells-possible relevance to autism spectrum disorders," PLoS One, vol. 9, no. 8, article e103740, 2014.

[100] R. Keşli, C. Gökçen, U. Buluğ, and Y. Terzi, "Investigation of the relation between anaerobic bacteria genus clostridium and late-onset autism etiology in children," Journal of 
Immunoassay \& Immunochemistry, vol. 35, no. 1, pp. 101109, 2013.

[101] S. M. Finegold, "Therapy and epidemiology of autism-clostridial spores as key elements," Medical Hypotheses, vol. 70, no. 3, pp. 508-511, 2008.

[102] T. Buie, D. B. Campbell, G. J. Fuchs III et al., "Evaluation, diagnosis, and treatment of gastrointestinal disorders in individuals with ASDs: a consensus report," Pediatrics, vol. 125, Supplement 1, pp. S1-18, 2010.

[103] D. A. Rossignol and R. E. Frye, "Mitochondrial dysfunction in autism spectrum disorders: a systematic review and meta-analysis," Molecular Psychiatry, vol. 17, no. 3, pp. 290-314, 2012.

[104] M. Bresnahan, M. Hornig, A. F. Schultz et al., "Association of maternal report of infant and toddler gastrointestinal symptoms with autism: evidence from a prospective birth cohort," JAMA Psychiatry, vol. 72, no. 5, pp. 466-474, 2015.

[105] Y. Luo, S. Kuang, L. Xue, and J. Yang, "The mechanism of 5lipoxygenase in the impairment of learning and memory in rats subjected to chronic unpredictable mild stress," Physiology \& Behavior, vol. 167, pp. 145-153, 2016.

[106] U. N. Das, E. J. Ramos, and M. M. Meguid, "Metabolic alterations during inflammation and its modulation by central actions of omega-3 fatty acids," Current Opinion in Clinical Nutrition and Metabolic Care, vol. 6, no. 4, pp. 413-419, 2003.

[107] N. Jamali, C. M. Sorenson, and N. Sheibani, "Vitamin D and regulation of vascular cell function," American Journal of Physiology. Heart and Circulatory Physiology, vol. 314, no. 4, pp. H753-H765, 2018.

[108] H. Alfawaz, M. Al-Onazi, S. I. Bukhari et al., "The independent and combined effects of omega-3 and vitamin B12 in ameliorating propionic acid induced biochemical features in juvenile rats as rodent model of autism," Journal of Molecular Neuroscience, vol. 66, no. 3, pp. 403-413, 2018. 